\title{
Unpacking Healthcare Professionals' Work to Achieve Coherence in the Healthcare Journey of Elderly Patients: An Interview Study
}

This article was published in the following Dove Press journal: Journal of Multidisciplinary Healthcare

\author{
Marianne Kumlin $\mathbb{D}^{1-3}$ \\ Geir Vegar Berg ${ }^{2,4}$ \\ Kari Kvigne' \\ Ragnhild Helles $\varnothing$ (D) $^{3}$
}

'Department of Health and Nursing Sciences, Inland Norway University of Applied Sciences Elverum, Elverum, Norway; ${ }^{2}$ Innlandet Hospital Trust, Lillehammer, Norway; ${ }^{3}$ Department of Nursing Science, Institute of Health and Society, Faculty of Medicine, University of Oslo, Oslo, Norway; ${ }^{4}$ Department of Health Sciences, Faculty of Medicine and Health Sciences, Norwegian University of Science and Technology, Gjøvik, Norway

Correspondence: Marianne Kumlin Tel +4791594685

Email marianne.kumlin@inn.no
Aim: Today, seamless, person-centered healthcare is emphasized when dealing with elderly patients with comprehensive needs. Studies have uncovered a complex healthcare terrain. Despite a great deal of effort on the part of policy makers and healthcare providers, the work healthcare professionals undertake to develop seamless healthcare is still unclear. Therefore, the aim of this study was to uncover the work that healthcare professionals undertake to achieve coherent and comprehensive healthcare for elderly patients with multiple health problems during their journey through the complex healthcare terrain.

Methods: This study has an explorative design with individual interviews. Twenty-five healthcare professionals from primary and specialist care agreed to participate. A thematic analysis method was employed.

Results: The analyses revealed three central themes in the healthcare professionals' work to build coherence in the patients' care trajectory: Working to manage a patient's illness trajectory during the course of the patient's life, working to achieve a comprehensive overall picture, and considering multiple options in a "patchwork" terrain.

Conclusion: Healthcare professionals have a common understanding that hospital stays are a short part of the elderly person's journey in the healthcare system. In the comprehensive work to obtain the overall picture of the illness trajectory within the patient's life story, healthcare professionals emphasized the importance of working in an interdisciplinary manner. Interprofessional consulting and collaboration should be strengthened to build coherence in the older patient's complex care trajectory.

Keywords: older, care trajectory, complex healthcare, health personnel, interdisciplinary

\section{Background}

It has been emphasized that healthcare provided to elderly patients with comprehensive needs should be seamless and person-centered. ${ }^{1-4}$ However, the increasing specialization in healthcare has led to a fragmented health system. Indeed, specialization in the provision of care is not only present in specialist care, but also in primary care. ${ }^{5,6}$ This has resulted in health systems that are complex and challenging for patients and their next of kin to navigate; many feel that they are on a labyrinthine journey. ${ }^{7-9}$ This situation is further complicated by the fact that elderly patients with several health problems often need healthcare services at different organizational levels, in which numerous providers are involved. ${ }^{10}$

Patients with comorbidities are more vulnerable to fragmented healthcare services and can often experience uncertainty about who is responsible for their care. ${ }^{10}$ 
One reason for this is that intersectoral collaboration and communication for these patients are challenging and complex. ${ }^{11}$ It has been stated that increased specialization places healthcare personnel in professional "silos". ${ }^{10}$ Such boundaries must be eliminated to create seamless healthcare collaboration and communication across organizations and disciplines. ${ }^{2,12}$ A central aim of integrated care is to enhance the patient's experience during the care trajectory and to move from a fragmented system to one that is person-centered. ${ }^{12}$ Person-centered care can be defined as an approach in which the care provider tries to understand the patient's complaints not only in terms of illnesses, but also as expressions of the patient's unique individuality, tensions, conflicts, and problems. ${ }^{13}$

Interprofessional work implies integrated perspectives on patient care among workers in various professions. ${ }^{10}$ Professionals from different disciplines have a responsibility to foster the integration of services, especially with the growing burden of disease. ${ }^{2}$ In Norway, the government has highlighted the need for a holistic and comprehensive patient care pathway characterized by combining sub healthcare services to coordinate the patient's care. The goal is high quality treatment regardless of who is responsible for each sub healthcare service. Emphasis is thus on interdisciplinary collaboration and prioritization of the patient's needs. ${ }^{14}$

Today, there is a global trend of shorter hospital stays, while the creation of efficient patient pathways has been part of an overall goal to save time in healthcare delivery. ${ }^{15}$ On the other hand, studies have shown that increased work efficiency can have an impact on the delivery of healthcare that is consistent with patient needs. ${ }^{15,16}$ In recent decades, standardized care pathways have been developed to ensure patient safety, increase patient satisfaction, and optimize the use of resources to enable the best possible care for patients with specific health problems. ${ }^{12}$ However, most of the care pathways have been developed for single diseases. For elderly patients with multimorbidities, healthcare personnel can strive to adapt the linear and disease-specific pathway for the organization of care to ensure that it is in line with the patient's preferences. ${ }^{10,12}$

Several studies have revealed that providing coherent healthcare to patients with comprehensive health problems can be difficult and complex. ${ }^{4,10,17}$

In the effort to deliver integrated care, tension as well as a variety of cultures among different healthcare systems and professionals has been described. Healthcare practice is characterized by diverse systems and various work environments. $^{16,18,19}$

Attempts have been made to formalize the work of interconnecting and coordinating healthcare services by means of guidelines. Research on the organization of health services shows that healthcare professionals combine both formalized and non-formalized working methods in practice. However, much of this management and organizational work is not fully "visible" and formalized. ${ }^{20-22}$ Defining this "invisible" and non-formalized work is a prerequisite for developing the care organization and collaboration. $^{23}$

Despite a great deal of effort on the part of policy makers and healthcare professionals to ensure seamless experiences for patients throughout their care trajectories, the actual work undertaken to develop seamless care is still unclear. ${ }^{11,24}$ Unpacking the work healthcare professionals conduct to achieve seamless and comprehensive healthcare that corresponds with the elderly patients' journeys through the complex healthcare terrain can contribute new insights and understanding of the development of appropriate healthcare.

Therefore, the aim of this study was to uncover the work healthcare professionals undertake to achieve coherent and comprehensive healthcare for elderly patients with multiple health problems during their journey through the complex healthcare terrain.

\section{Methods}

This study employed an explorative design with individual interviews. This approach provided a broader insight into the healthcare professionals' perspectives on their efforts and work throughout the elderly patients' journey through the healthcare system. The question under investigation was part of a larger project that studied the care trajectory of elderly patients. In the project we explored how elderly patients engage in and interact with their care trajectory across different healthcare systems. ${ }^{25}$ The focus of this paper is how healthcare professionals attempt to achieve coherence in the patients' care trajectory. The data collection was conducted from November 2017 to June 2018. This study complies with the Consolidated Criteria for Reporting Qualitative Research (COREQ) [Supplementary file 1].

\section{Setting and Participants}

The Norwegian healthcare system consists of two organizational structures and financial systems. Primary health care is organized and financed by the 
municipalities, while specialist care is owned by the national health authorities. The local authorities are responsible for planning and providing primary care services, which include the provision of general practitioners (GP) municipal emergency care units, home care services, sheltered housing, nursing homes, preventive services, and intermediate care. The national authorities are responsible for providing specialist care, which encompasses all hospitals and outpatient clinics. National priorities are communicated through policy documents and guidelines for professionals. In recent decades there has been a transfer of rehabilitation and follow up-care tasks from specialist to primary care. ${ }^{26,27}$ There is ongoing discussion about the challenges involved in the transfer of these tasks, including the allocation of resources, both financial and in terms of skills and competencies/responsibility. ${ }^{28,29}$

A purposive sampling of healthcare professionals who were involved in the care trajectories of the larger research project $^{25}$ was chosen. The participants were recruited from both primary and specialist care. They represented one rural hospital, one urban hospital and six different municipalities. The population of the municipalities ranged from 2000 to 27,000 inhabitants. The healthcare professionals were given verbal and written information about the study by the department manager and the first author. The inclusion criteria were: working as a healthcare professional who cares for elderly patients and has a minimum of a bachelor's degree. Twenty-five healthcare professionals consented to participate in the study (Table 1). Three health healthcare professionals refused to participate because of workflow and time issues. No one dropped out during the study.

\section{Data Collection}

All interviews were conducted by the first author at the participants' workplace with only the researcher and participant present. The interviews varied in length from 20-45 $\mathrm{min}$ and an interview guide was used. After the first interview some corrections were made to

Table I Participants Interviewed

\begin{tabular}{|l|l|l|}
\hline Participant $^{\mathbf{a}}$ & Hospital $^{\mathbf{b}}$ & Primary Care $^{\mathbf{b}}$ \\
\hline Occupational therapists & 1 & 2 \\
Physicians & 5 & 3 \\
Physiotherapists & 2 & \\
Nurses & 5 & 7 \\
\hline
\end{tabular}

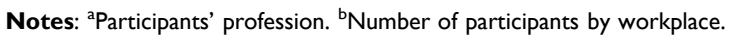

the guide to make the content clearer and broaden the questions. The questions focused on the healthcare professionals' descriptions of elderly patients with complex health problems during the care trajectory, their experiences of the guidelines and standardization of care during the trajectory, and their perspectives on integrated and coordinated healthcare. The participants were encouraged to talk openly by asking open-ended questions, and the interview guide was used to lead into pertinent topics in the research. Reflective field notes were made after each interview and facilitated the discussion about data saturation. ${ }^{30}$ No repeat interviews were conducted.

\section{Ethical Considerations}

The Norwegian Centre for Research Data has been notified about the study (ID: 54,551). Participation was based on informed, voluntary consent.

The informed consent included the use of anonymized responses. The participants were told that they could withdraw from the study at any time without consequences. No participant in this study was in a dependent relationship with the researcher (first author).

\section{Analysis}

The interviews were audio recorded and transcribed verbatim by the first author. All data were de-personalized before analysis. Braun and Clarke's ${ }^{31}$ thematic analysis approach was applied. Initially, we read the interviews thoroughly to identify essential preliminary characteristics and patterns. Notes were taken to record the descriptive and analytical attributes of the data. Thereafter, the data were read and systematically coded manually, after which the codes were organized into possible subthemes. The back-and-forth process between coding and organizing the data into possible subthemes involved reviewing relevant research and theoretical perspectives to enhance understanding of the data. When disagreement between the members of the research group occurred, we discussed the themes with reference to the aim of study until a common understanding was achieved. This process revealed three main themes. An example of the analysis process can be found in Table 2 .

\section{Findings}

Overall, the findings show that in the work to build coherence in the patients' journey through the healthcare system, healthcare professionals could not ignore the elderly 
Table 2 Example of the Analysis Process

\begin{tabular}{|l|l|l|}
\hline Example of Codes & $\begin{array}{l}\text { Example of the Development from } \\
\text { Codes to Subthemes }\end{array}$ & Identified Theme \\
\hline For the patient it is a lifelong journey. & $\begin{array}{l}\text { Organizing the illness trajectory in parallel } \\
\text { with the long-term trajectory. }\end{array}$ & $\begin{array}{l}\text { Working to manage the illness trajectory during } \\
\text { the course of the patient's life. }\end{array}$ \\
\hline $\begin{array}{l}\text { "Shorter" illness trajectories impact on the } \\
\text { patient's life. }\end{array}$ & Taking account of the patient's life. & \\
\hline $\begin{array}{l}\text { Worsening of illness or just a change in the } \\
\text { need for healthcare. }\end{array}$ & $\begin{array}{l}\text { Considering follow-up in the patient's living } \\
\text { environment. }\end{array}$ & \\
\hline $\begin{array}{l}\text { Patients' involvement in their housing } \\
\text { arrangements. }\end{array}$ & & \\
\hline $\begin{array}{l}\text { Early contact with healthcare in the long-term } \\
\text { pathway. }\end{array}$ & & \\
\hline $\begin{array}{l}\text { Important to have knowledge of the patient's } \\
\text { life situation and network. }\end{array}$ & & \\
\hline $\begin{array}{l}\text { Organising is laborious and must be seen in } \\
\text { connection with the patient's life. }\end{array}$ & & \\
\hline $\begin{array}{l}\text { Not thinking too much about the diagnosis but } \\
\text { more about the person. }\end{array}$ & & \\
\hline
\end{tabular}

patient's life. Planning and facilitating the patients' healthcare was described as a long-term activity, often for life. Healthcare professionals worked to achieve a complete and comprehensive picture of the patient's situation in the patchwork terrain of the healthcare service.

The analysis revealed three central themes involved in the healthcare professionals' work to build coherence in the patient's care trajectory: Working to manage the illness trajectory during the course of the patient's life, working to achieve a comprehensive overall picture, and considering multiple options in a "patchwork" terrain.

\section{Working to Manage the Illness Trajectory During the Course of the Patient's Life}

The healthcare professionals expressed that when a patient becomes dependent on long-term care, they cannot ignore other aspects of patients' life. There was a common understanding that the care trajectory of the elderly patient lasts for a long time, often until death. The advent of a need for diverse healthcare services was described as a natural part of the patient's lifecycle. Healthcare professionals stated that this long-term care could be interrupted by a shorter ("stop-over") trajectory that results in a change in the level of health services or need for medical treatment. The interruptions during the long-term care trajectory could be related to a worsening of the illness but might also be just a change in the need for health and social services.

And then, it is really the trajectory of the patient's entire period from being admitted to being ... until they actually die. Even if one prefers not to use the term 'patient' in order not to make people 'sick' who are really just old.

Hospital stays were not necessarily always involved in these interruptions in the care trajectory, as described by an occupational therapist:

What I think is that when you become ill or something happens to you, the (GP) may be the first to see you, if there is no emergency. If there is something that needs treatment then maybe you have to go to the hospital, maybe connect to home care in advance via a GP or relatives ... and sometimes the hospital does not have to be involved either, but most of the time it is, at some point.

Healthcare professionals in municipalities described that this long-term trajectory could begin at an early phase in which the need for healthcare could be low, similar to a "dormant phase". Early contact with the healthcare system could be in the form of support from a volunteer center, preventive home visits, GPs, and/or home care. Healthcare professionals in municipalities see themselves as having longer relationships with the patient. Hospital 
personnel perceived themselves to have a more temporary role in this long-term trajectory. When their contact with the patient ended, their trajectory with that patient was over and the patient continued on in the system.

For the patient, it is a lifelong process, for us the process is from admission and what we can do about it at that time and then the patient goes further or home.

Regarding planning and facilitation throughout the care trajectory, it was necessary to take the patient's life into account. A prerequisite was a certain amount of knowledge about the patient's life situation and network.

"Shorter" illness trajectories could make an impact on the patient's life. Healthcare professionals expressed expectations as to patients' levels of involvement, for example, in taking care of their housing arrangements.

The elderly think too late about changing residence. It goes so far that when they do need help, the threshold for moving will probably be higher than if they had considered it earlier.

Facilitating follow-up in the home changed the care trajectory framework and prerequisites. It was expressed that when patients went home, they wanted to make their own decisions concerning their daily life and to control things themselves. In the home, there could be several actors around the patient, such as a spouse and children, with their own perceptions and opinions. Healthcare professionals had to relate to and communicate with patients and next of kin at the same time as being expected to follow-up on what had been decided at the hospital

"At the same time it is not just 'running' into the living room" and determining what the healthcare professionals in the hospital expect to be done.

\section{Working to Achieve a Comprehensive Overall Picture}

Assessing the treatment and developing a care plan are dependent on having a certain amount of knowledge about the patients. Healthcare professionals in hospitals and municipalities emphasized the importance of gaining a comprehensive picture of the patient. They described that it could take time and a great deal of work to obtain an overview of a patient's situation. It was necessary to see the entirety of a patient's situation during the hospital stay and further follow-up in the municipality, as expressed by a doctor in the hospital:
You have to pay attention to what happens after the hospital stay. I think that is typical.

A nurse in the municipality described the need in the following way:

We have to scan every single patient's situation; there is a lot that has to be reasoned around in order to ensure a quality patient trajectory.

Healthcare professionals agreed on the importance of interdisciplinary approaches and collaboration methods. It could be appropriate to become acquainted with the patient over time when many decisions need to be made during the care trajectory.

On the other hand, comprehensive healthcare was also expressed in more medical terms. The patient should experience the treatment as holistic and individually adapted.

We want the care trajectory to be a smooth treatment line - and adapted to your situation - the best possible overall, integral experience and treatment.

Despite the fact that the importance of an interdisciplinary approach was emphasized, descriptions of practice indicated that this was coincidental mode of work.

It is a bit casual or random how it is followed up, I must say. Who catches up ... and which professional group visits the patient the most? Who asks the questions about how the patient is now? And these interdisciplinary meetings that we have, it is a bit casual I think.

When describing the interdisciplinary mode of work, healthcare professionals were aware of the work of other professions, but at the same time it was not necessarily a practice characterized by interaction, as a GP described:

It is appropriate to have an interdisciplinary understanding of the patient. We do not always have the same understanding. I do not know everything about the functional level and suchlike. And the decisions taken in the forums where doctors are not involved at all? It will be "twofold".

\section{Considering Multiple Options in}

\section{a "Patchwork" Terrain}

The healthcare professionals in hospitals expressed that they had to consider a diversity of arenas for deciding on the best options for the patients after discharge. Such arenas appeared almost like a patchwork with multiple possibilities. For example, they considered whether a nursing home, 
sheltered unit, rehabilitation unit, home or other facility would be best for a patient. In hospitals, the doctors often needed to consider if the patient should receive medical treatment and follow-up in general practice or in specialist care. These considerations were a result of what they expressed as the politics of "emptying beds". One hospital doctor described it as follows:

Many patients need to stay somewhere else [other than in a hospital] because their stay here is so short. And if you are sick and need treatment and can get it somewhere else, then you should go elsewhere.

The healthcare professionals in the municipalities considered whether the patient fulfilled criteria related to one of the care models they provided. Such criteria included whether healthcare could be delivered in the patient's home, in a nursing home, in a short-term specialized unit or in an intermediate unit. They described considerations such as the allocation of staff resources, the patient's needs, and options in the decision-making process.

What our team does is to ... first, we have our case manager on an assessment visit at the short-term ward, the nursing home or at another institution and then we decide if there is rehabilitation potential.

The necessary resources to facilitate professional assessments as well as training and rehabilitation interventions were often lacking.

One has to be in bad shape to get a rehabilitation bed and we know that it is very difficult to get patients further, which is a dilemma for those who need a rehabilitation place.

However, it was not only the patient's health situation that was considered. Hospital personnel's assessments of where the patient should receive follow-up care and their knowledge of local municipalities also played an important role. One consideration was whether or not municipalities had the capacity and competence. The hospital doctors sometimes expressed concern about "letting the patient go", as they were unsure where the patient would go next and understood that it was not always easy to arrange the best treatment and follow-up at home.

When treatment is moved out of the hospital, we have to be realistic; we cannot expect very advanced treatment outside of the hospital.
The healthcare professionals in the municipalities also reflected on the patients' situation. Although the hospital doctors expressed concern about where the patient was going next, the GPs described the need for more extensive feedback on the patient's health problems. The GPs considered themselves to have a central role in the follow-up process based on the fact that they had broad knowledge of the patient and her/his network.

As a GP, I think that getting a comprehensive assessment is what we struggle a lot with. We must try to get help with complex issues.

The other healthcare professionals in the municipalities stated that they had a responsibility to facilitate follow-up and healthcare after a hospital stay. When doing so, they relied on their previous knowledge of the patient and expressed that they were often familiar with patients' lives and networks.

\section{Discussion}

The effort to build coherence in the patients' journey through the healthcare system involves comprehensive work for healthcare professionals. Our analysis showed that they had to build an overall picture of the patient's illness trajectory within their life story. They emphasized the importance of working in an interdisciplinary manner to gain such a complete and comprehensive picture of the patient. Their considerations about the best options for the patient after discharge involved multiple negotiations within the unscripted patchwork of the healthcare terrain.

In contrast to our findings, previous studies have revealed tensions between healthcare professionals in hospitals and municipalities regarding the perceptions of patients' readiness for discharge and different perspectives on the need for healthcare after discharge. ${ }^{16,19}$ We identified that healthcare professionals seemed to have a common perception and an acceptance of the fact that for older patients, a hospital stay is just a short part of the longer care trajectory. This common understanding influenced their work when they negotiated about the best options for patients after discharge.

According to Schot et al, ${ }^{11}$ it is the responsibility of healthcare professionals to negotiate overlaps in the individual care process, patient transfer issues, and discussions of where patients should go. We discovered that healthcare professionals consider multiple options for the follow-up care of patients in a diversity of arenas after discharge. In the municipality, the healthcare professionals considered whether the patient fulfilled criteria related to one of the 
care models they provided. The challenges of working in this "patchwork" terrain entail a diversity of healthcare overlap, where the following are arenas that require a high level of negotiation.

The short hospital stay entailed deliberations about whether continuing medical treatment was an option at hospital level or in primary care. Furthermore, the healthcare professionals based their considerations on their insight into local capacity, knowledge and competency. In studies, it has been discussed what being ready for discharge means, especially in the context of short hospital stays and complex health problems. ${ }^{15,16,19}$ The need for hospital staff to free hospital beds is well known ${ }^{17,32}$ and consistent with our findings in which healthcare professionals referred to this phenomenon as the politics of "emptying beds".

The process of negotiating healthcare overlaps is not just about finding practical solutions for releasing beds ${ }^{17}$ and considering available resources, but also involves taking each patient's situation into account. Throughout their journey in the healthcare system patients play a role in negotiations regarding their need for healthcare and deliberations about necessary changes in their living arrangements. The negotiation between patients, healthcare professionals and next of kin was often ongoing. ${ }^{25}$ The need for knowledge across the organizations is mutual and may require a change in the approach to negotiation and interaction. ${ }^{11}$

In order to manage the patient's journey in the healthcare system, healthcare professionals in hospitals and in the municipalities described the need for broader knowledge about the patient's illness trajectory within her/his daily life. They expressed the importance of achieving a comprehensive picture of the patient. The need for an interprofessional approach and collaboration was emphasized in the work to achieve this comprehensive picture. While healthcare professionals highlighted the need for knowledge of other health professions, they nevertheless described a practice where interprofessional collaboration was coincidental and not intentional.

Challenges concerning the multiple considerations regarding healthcare services were described in our study. The development of specialization and differentiation can contribute to the overall quality of healthcare. ${ }^{12,18}$ Therefore, it can be advantageous not to minimize differentiation, but at the same time to focus on integration. A high level of coordination and collaboration will be required to increase integration. ${ }^{18}$ Research has shown that the ways in which professionals consult each other can result in the provision of a high level of qualitative care and integrated practice. ${ }^{11}$ Our participants emphasized the need for interdisciplinary collaboration for this patient group. However, their perception of what "interprofessional consulting" is was not obvious and seemed to be confined to their own profession, which is supported by other studies. ${ }^{33}$ It is a challenge that record systems do not link access to various levels and different professions, which can lead to gaps in the information or to information overlaps. $^{10,34}$ In addition, research has identified that healthcare professionals also need to create space for communication and knowledge transfer to ensure the quality of care. $^{11}$

Our study revealed that the elderly patients' journey in the healthcare system is not straightforward and healthcare professionals did not have a clear script to follow. It may be possible that the absence of a "script" has an impact on the gaps in the interdisciplinary work in a changing "patchwork" healthcare terrain, where treatment and follow-up take place in the home to a greater extent. Facilitating follow-up in the home changed the healthcare framework and prerequisites. Other negotiations and collaborative transfers are required for healthcare professionals to provide care in patients' homes, where the patient and next of kin are expected to play a collaborative role. $^{35}$

An example of a type of "script" might be standardized care pathways, described in the literature as possible tools to bridge gaps in collaboration and articulation of knowledge surrounding healthcare. One intention is to strengthen the predictability and quality of treatment. ${ }^{36}$ However, to function properly, these care pathways should be relevant to healthcare practice and be able to be maneuvered by those involved. ${ }^{12}$ So far, standardized care pathways have been diagnosis specific and do not fit into the picture of the complex patient trajectories and life stories of elderly patients. ${ }^{10,37}$ Care trajectories that cannot be pushed into a script may make it more challenging to find common goals and approaches in healthcare practice.

\section{Strengths and Limitations}

A strength of this study is the diversity of the participants in terms of profession and workplaces (hospital and primary care). Although whether saturation was achieved is questionable, the data material provided thick and rich information, which contributed new insights into how 
healthcare professionals work to build coherence in older patients' care trajectory. A limitation is that we were unable to take our analysis and interpretations back for a member check ${ }^{38}$ because of the variety of workplaces and distances between them.

The first author is an experienced geriatric nurse, which might have influenced the focus of the interviews. However, her experiences may also open up for questions that otherwise would not have been addressed. Thus, the preunderstanding and assumptions might have influenced the data collection and interpretation of the data. To strengthen the trustworthiness, the entire research group reflected on and discussed the data throughout all phases of the research process and in particular during the analysis phase.

\section{Conclusion}

Healthcare professionals have a common understanding that hospital stays are only a short part of elderly patients' journey in the healthcare system and that they must take account of the elderly patient's life. Building an overall picture of the patient beyond the illness trajectory and within her/his life is important for managing the care trajectory. Interdisciplinary work is highlighted as expedient for achieving this complete and comprehensive picture. For this purpose, the findings in our study indicate that interprofessional consulting and collaboration should be strengthened in the work to build coherence within the complex care trajectory of elderly patients.

\section{Data Sharing Statement}

The data that support the findings of this study are available from the Innlandet Hospital trust Norway, but restrictions apply to the availability of these data, which were used under license for the study and so are not publicly available.

\section{Ethical Approval and Informed Consent}

The Norwegian Centre for Research Data (NSD) was notified about the project, ID: 54,551. The NSD assessed that the processing of personal data was regulated in The Personal Data Regulations 465 [Forskrift om behandling av personopplysninger]. Participation in this research was based on informed voluntary consent and all participants received verbal and written information about the study and were free to withdraw at any time. All participants signed an informed consent form.

\section{Consent for Publication}

The written consent form contains information that the publication of the study results will be in anonymous form so that the participants cannot be identified.

\section{Acknowledgments}

We would like to express our sincere thanks to the healthcare professionals who participated in this study.

\section{Funding}

This project is funded by a grant from the Inland Norway University of Applied Sciences and a grant from the Innlandet Hospital trust Norway. The funding bodies had no role in the design of the study, the data collection, the analysis and the interpretation of data or the writing of the manuscript.

\section{Disclosure}

The authors report no conflicts of interest in this work.

\section{References}

1. Reed J, Cook G, Childs S, McCormack B. A literature review to explore integrated care for older people. Int J Integr Care. 2005;5: e17. doi:10.5334/ijic.119

2. Valentijn PP, Schepman SM, Opheij W, Bruijnzeels MA. Understanding integrated care: a comprehensive conceptual framework based on the integrative functions of primary care. Int $J$ Integr Care. 2013;13(1):655-679. doi:10.5334/ijic.886

3. Grimsmo A, Løhre A, Røsstad T, Gjerde I, Heiberg I, Steinsbekk A. Helhetlige pasientforløp-gjennomføring i primærhelsetjenesten [Implementation of clinical pathways in primary care]. Tidsskrift Omsorgsforskning. 2016;2(2):78-87. doi:10.18261/issn.2387-59842016-02-02

4. Everink IHJ, van Haastregt JCM, Tan FES, Schols J, Kempen G. The effectiveness of an integrated care pathway in geriatric rehabilitation among older patients with complex health problems and their informal caregivers: a prospective cohort study. BMC Geriatr. 2018;18 (1):285. doi:10.1186/s12877-018-0971-4

5. Røsstad T, Garåsen H, Steinsbekk A, Sletvold O, Grimsmo A. Development of a patient-centred care pathway across healthcare providers: a qualitative study. BMC Health Serv Res. 2013;13 (1):1-9. doi:10.1186/1472-6963-13-121

6. Elliott J, Stolee P, Boscart V, Giangregorio L, Heckman G. Coordinating care for older adults in primary care settings: understanding the current context. BMC Fam Pract. 2018;19(1):137. doi:10.1186/s12875-018-0821-7

7. Foss C, Hofoss D, Romøren TI, Bragstad LK, Kirkevold M. Elderly persons' experiences with hospital discharge. Sykepleien Forskning. 2012;7(4).

8. Bragstad LK, Kirkevold M, Foss C. The indispensable intermediaries: a qualitative study of informal caregivers' struggle to achieve influence at and after hospital discharge. BMC Health Serv Res. 2014;14(1):1. doi:10.1186/1472-6963-14-331

9. Neiterman E, Wodchis WP, Bourgeault IL. Experiences of older adults in transition from hospital to community. Can J Aging. 2015;34(1):90-99. doi:10.1017/S0714980814000518

10. Doessing A, Burau V. Care coordination of multimorbidity: a scoping study. J Comorb. 2015;5(1):15-28. doi:10.15256/joc.2015.5.39 
11. Schot E, Tummers L, Noordegraaf M. Working on working together. A systematic review on how healthcare professionals contribute to interprofessional collaboration. $J$ Interprof Care. 2020;34 (3):332-342. doi:10.1080/13561820.2019.1636007

12. Haland E, Rosstad T, Osmundsen TC. Care pathways as boundary objects between primary and secondary care: experiences from Norwegian home care services. Health. 2015;19(6):635-651. doi:10.1177/1363459314567789

13. Uijen AA, Schers HJ, Schellevis FG, van den Bosch WJ. How unique is continuity of care? A review of continuity and related concepts. Fam Pract. 2012;29(3):264-271. doi:10.1093/fampra/cmr104

14. Ministry of Health and Care Service. The Primary Health and Care Services of Tomorrow - Localised and Integrated Helsetjeneste. Report No. 26 to the Storting. (2014-2015). Oslo: Departmentet; 2014.

15. Bendix Andersen A, Beedholm K, Kolbæk R, Frederiksen K. When clock time governs interaction: how time influences health professionals' intersectoral collaboration. Qual Health Res. 2018;28 (13):2059-2070. doi:10.1177/1049732318779046

16. Petersen HV, Foged S, Nørholm V. "It is two worlds" cross-sectoral nurse collaboration related to care transitions: a qualitative study. J Clin Nurs. 2019;28(9-10):1999-2008. doi:10.1111/jocn.14805

17. Allen D, Griffiths L, Lyne P. Understanding complex trajectories in health and social care provision. Sociol Health Illn. 2004;26 (7):1008-1030. doi:10.1111/j.0141-9889.2004.00426.x

18. Glouberman S, Mintzberg H. Managing the care of health and the cure of disease - part I: differentiation. Health Care Manage Rev. 2001;26(1):56-69. doi:10.1097/00004010-200101000-00006

19. Hellesø R, Fagermoen MS. Cultural diversity between hospital and community nurses: implications for continuity of care. Int $J$ Integr Care. 2010;10(1). doi:10.5334/ijic.508

20. Allen D. The Invisible Work of Nurses: Hospitals, Organisation and Healthcare. Routledge; 2014.

21. Allen D. Care trajectory management: a conceptual framework for formalising emergent organisation in nursing practice. J Nurs Manag. 2019;27(1):4-9. doi:10.1111/jonm.12645

22. Halbesleben JR, Wakefield DS, Wakefield BJ. Work-arounds in health care settings: literature review and research agenda. Health Care Manage Rev. 2008;33(1):2-12. doi:10.1097/01.HMR.0000304495.95522.ca

23. Nardi BA, Engeström Y. A web on the wind: the structure of invisible work. Comput Support Coop Work. 1999;8(1-2):1-8. doi:10.1023/ A:1008694621289

24. Allen D. Re-conceptualising holism in the contemporary nursing mandate: from individual to organisational relationships. Soc Sci Med. 2014;119:131-138. doi:10.1016/j.socscimed.2014.08.036
25. Kumlin M, Berg GV, Kvigne K, Hellesø R. Elderly patients with complex health problems in the care trajectory: a qualitative case study. $B M C$ Health Serv Res. 2020;20(1):1-10. doi:10.1186/s12913-020-05437-6

26. Grimsmo A, Lohre A, Rosstad T, Gjerde I, Heiberg I, Steinsbekk A. Disease-specific clinical pathways - are they feasible in primary care? A mixed-methods study. Scand J Prim Health Care. 2018;36 (2):152-160. doi:10.1080/02813432.2018.1459167

27. Sogstad M, Hellesø R, Skinner MS. The development of a new care service landscape in Norway. Health Serv Insights. 2020;13:1178632920922221. doi:10.1177/1178632920922221

28. Bing-Jonsson PC, Foss C, Bjørk IT. The competence gap in community care: imbalance between expected and actual nursing staff competence. Nord J Nurs Res. 2015;36(1):27-37. doi:10.1177/ 0107408315601814

29. Gautun H, Syse A. Earlier hospital discharge: a challenge for Norwegian municipalities. Nord J Soc Res. 2017;8.

30. Polit DF, Beck CT. Nursing Research: Generating and Assessing Evidence for Nursing Practice. 9th ed. Philadelphia, Pa: Wolters Kluwer Health; 2012.

31. Braun V, Clarke V. Using thematic analysis in psychology. Qual Res Psychol. 2006;3(2):77-101. doi:10.1191/1478088706qp063oa

32. Andersen AB, Beedholm K, Kolbæk R, Frederiksen K. The role of 'mediators' of communication in health professionals' intersectoral collaboration: an ethnographically inspired study. Nurs Inq. 2019;26 (4):e12310. doi:10.1111/nin. 12310

33. Wibe T, Ekstedt M, Hellesø R. Information practices of health care professionals related to patient discharge from hospital. Inform Health Soc Care. 2015;40(3):198-209. doi:10.3109/17538157.2013.879150

34. Melby L, Obstfelder A, Hellesø R. "We tie up the loose ends": homecare nursing in a changing health care landscape. Glob Qual Nurs Res. 2018;5:2333393618816780. doi:10.1177/2333393618816780

35. Mattingly C, Grøn L, Meinert L. Chronic homework in emerging borderlands of healthcare. Cult Med Psychiatry. 2011;35(3):347-375. doi:10.1007/s11013-011-9225-z

36. De Bleser L, Depreitere R, De Waele K, Vanhaecht K, Vlayen J, Sermeus W. Defining pathways. J Nurs Manag. 2006;14(7):553-563. doi:10.1111/j.1365-2934.2006.00702.x

37. Skrove GK, Bachmann K, Aarseth T. Integrated care pathways - a strategy towards better care coordination in municipalities? A qualitative study. Int J Integr Care. 2016;19(1-2):20-28.

38. Creswell JW, Miller DL. Determining validity in qualitative inquiry. Theory Pract. 2000;39(3):124-130. doi:10.1207/s15430421tip3903_2
Journal of Multidisciplinary Healthcare

\section{Publish your work in this journal}

The Journal of Multidisciplinary Healthcare is an international, peerreviewed open-access journal that aims to represent and publish research in healthcare areas delivered by practitioners of different disciplines. This includes studies and reviews conducted by multidisciplinary teams as well as research which evaluates the results or conduct of such teams or healthcare processes in general. The journal covers a very wide range of areas and welcomes submissions from practitioners at all levels, from all over the world. The manuscript management system is completely online and includes a very quick and fair peer-review system. Visit http://www.dovepress.com/testimonials. php to read real quotes from published authors. 